\title{
Elderly Black Non-Hispanic Patients With Head and Neck Squamous Cell Cancer Have the Worst Survival Outcomes
}

Jessica D. McDermott, MD'; Megan Eguchi, MPH²; Rustain Morgan, MD³; Arya Amini, MD; Julie A. Goddard, MD; Evelinn A. Borrayo, $\mathrm{PhD}^{2}$; and Sana D. Karam, MD, PhD ${ }^{6}$

\begin{abstract}
Background: In this population study, we compared head and neck cancer (HNC) prognosis and risk factors in 2 underserved minority groups (Hispanic and Black non-Hispanic patients) with those in other racial/ethnicity groups. Methods: In this SEER-Medicare database study in patients with HNC diagnosed in 2006 through 2015, we evaluated cancer-specific survival (CSS) between different racial/ ethnic cohorts as the main outcome. Patient demographics, tumor factors, socioeconomic status, and treatments were analyzed in relation to the primary outcomes between racial/ethnic groups. Results: Black non-Hispanic patients had significantly worse CSS than all other racial/ethnic groups, including Hispanic patients, in unadjusted univariate analysis (Black non-Hispanic patients: hazard ratio, 1.48; 95\% Cl, 1.33-1.65; Hispanic patients: hazard ratio, 1.12; $95 \% \mathrm{Cl}, 0.99-1.28)$. To investigate the association of several variables with CSS, data were stratified for multivariate analysis using forward Cox regression. This identified socioeconomic status, cancer stage, and receipt of treatment as predictive factors for the survival differences. Black non-Hispanic patients were most likely to present at a later stage (odds ratio, $1.62 ; 95 \% \mathrm{Cl}, 1.38-1.90$ ) and to receive less treatment (odds ratio, $0.67 ; 95 \% \mathrm{Cl}, 0.55-0.81$ ). Unmarried status, high poverty areas, increased emergency department visits, and receipt of healthcare at non- $\mathrm{NCl} /$ nonteaching hospitals also significantly impacted stage and treatment. Conclusions: Black nonHispanic patients have a worse HNC prognosis than patients in all other racial/ethnic groups, including Hispanic patients. Modifiable risk factors include access to nonemergent care and prevention measures, such as tobacco cessation; presence of social support; communication barriers; and access to tertiary centers for appropriate treatment of their cancers.
\end{abstract}

J Natl Compr Canc Netw 2021;19(1):57-67 doi: 10.6004/jnccn.2020.7607

\footnotetext{
${ }^{1}$ Department of Medical Oncology, ${ }^{2}$ Department of Health Systems, Management and Policy, and ${ }^{3}$ Department of Radiology, University of Colorado Anschutz School of Medicine, Aurora, Colorado; ${ }^{4}$ Department of Radiation Oncology, City of Hope, Duarte, California; and ${ }^{5}$ Department of Otolaryngology, and ${ }^{6}$ Department of Radiation Oncology, University of Colorado Anschutz School of Medicine, Aurora, Colorado.
}

\section{Background}

Approximately 65,000 new cases of head and neck cancer (HNC) are diagnosed in the United States annually, with 13,500 cancer-related deaths. ${ }^{1} \mathrm{HNC}$ has discrepancies in presentations and outcomes across different racial and ethnic cohorts. Laryngeal cancer has a $50 \%$ higher incidence in Black non-Hispanic (NH) men, and nasopharyngeal carcinoma has a higher incidence in Asian $\mathrm{NH}$ individuals. ${ }^{2-4}$ Oropharyngeal and oral cavity cancers have similar incidence rates across cohorts, although the prevalence of HPV, a significant positive prognostic factor, is much lower in Black individuals. ${ }^{5,6}$

Despite ongoing advancements in surgery, radiation therapy (RT), and chemotherapy, survival in HNC remains poor, particularly among Black patients. ${ }^{7}$ Multiple studies examining racial/ethnic disparities have found worse outcomes in Black NH patients than in White NH patients, although there has not been a comparison with Hispanic patients. ${ }^{8-15}$ These studies have attributed the differences in outcomes to differences in socioeconomic status, cancer stage at presentation, insurance coverage, and treatment patterns.

The present analysis explores differences in racial/ ethnic disparities associated with cancer outcomes in patients with HNC during the modern era. We used updated SEER-Medicare population data to derive information on patient and tumor characteristics and treatment, payment, and healthcare use data to control for bias of different healthcare/insurance coverage. We focused our comparisons on 2 historically underserved populations (Hispanic and Black $\mathrm{NH}$ patients) and aimed to find modifiable predictors that could result in changes in care patterns to achieve equity between the different racial/ethnic cohorts.

\section{Methods}

Data

The SEER-Medicare linked database was used to conduct a retrospective cohort observational study. SEER includes

See JNCCN.org for supplemental online content. 
person-level information on cancer survival and incidence from 18 population-based tumor registries encompassing approximately $28 \%$ of the population ${ }^{16}$ and containing demographic data, diagnosis date, cancer site, and cancer stage. The linked Medicare data include claims for beneficiaries with fee-for-service coverage and date of death. Medicare payments, patient deductibles, and copayments are included with each Medicare claim, together with dates of service and codes for diagnoses and procedures. This project was reviewed by the Colorado Multiple Institutional Review Board and was deemed exempt due to the deidentified status of the data.

\section{Cohort Selection}

Patients selected had squamous cell HNC (ICD-O-3 site codes C00.X-C14.X, C32.X; morphology codes 8050-8089) as the first and only tumor diagnosed in 2006 through 2015 (Figure 1). To capture patients with at least 1 year of prior Medicare eligibility, we included patients aged $\geq 66$ years at diagnosis. We excluded patients with an unknown diagnosis date, diagnosed at death, and with unknown stage, race/ethnicity, and poverty or rural-urban commuting area (RUCA) measure. Patients were continuously enrolled in Medicare fee-for-service Parts A and B for 12 months before and after diagnosis with at least 1 paid medical claim in the 12 months after diagnosis. A total of 13,117 patients met the inclusion criteria.

\section{Outcomes}

Primary outcomes included overall survival (OS) and cancer-specific survival (CSS), stage at diagnosis, and receipt of treatment. OS was measured from diagnosis date to Medicare reported date of death through December 2016. CSS was calculated using SEER-reported survival months through December 2015, accounting for the cause of death. These time periods differ because of respective follow-up times in the linked SEER and Medicare databases. Survival was censored at 36 months. Cancer stage at diagnosis was based on the AJCC Cancer Staging Manual, 6th edition and was defined as early (stages I/II) and late (stages III/IV). Treatment was defined as any surgery, RT, and/or chemotherapy initiated within 6 months from diagnosis. These analyses were repeated between the 2 minority groups: Black $\mathrm{NH}$ individuals and Hispanic individuals. Time to treatment (treatment delay) was a secondary outcome calculated as days from the earliest diagnostic procedure to treatment start.

\section{Covariates}

SEER was used for patient age at diagnosis, race/ethnicity, marital status, geographic region, census tract RUCA code, census tract percentage below the poverty level, Charlson comorbidity score, and tumor characteristics.

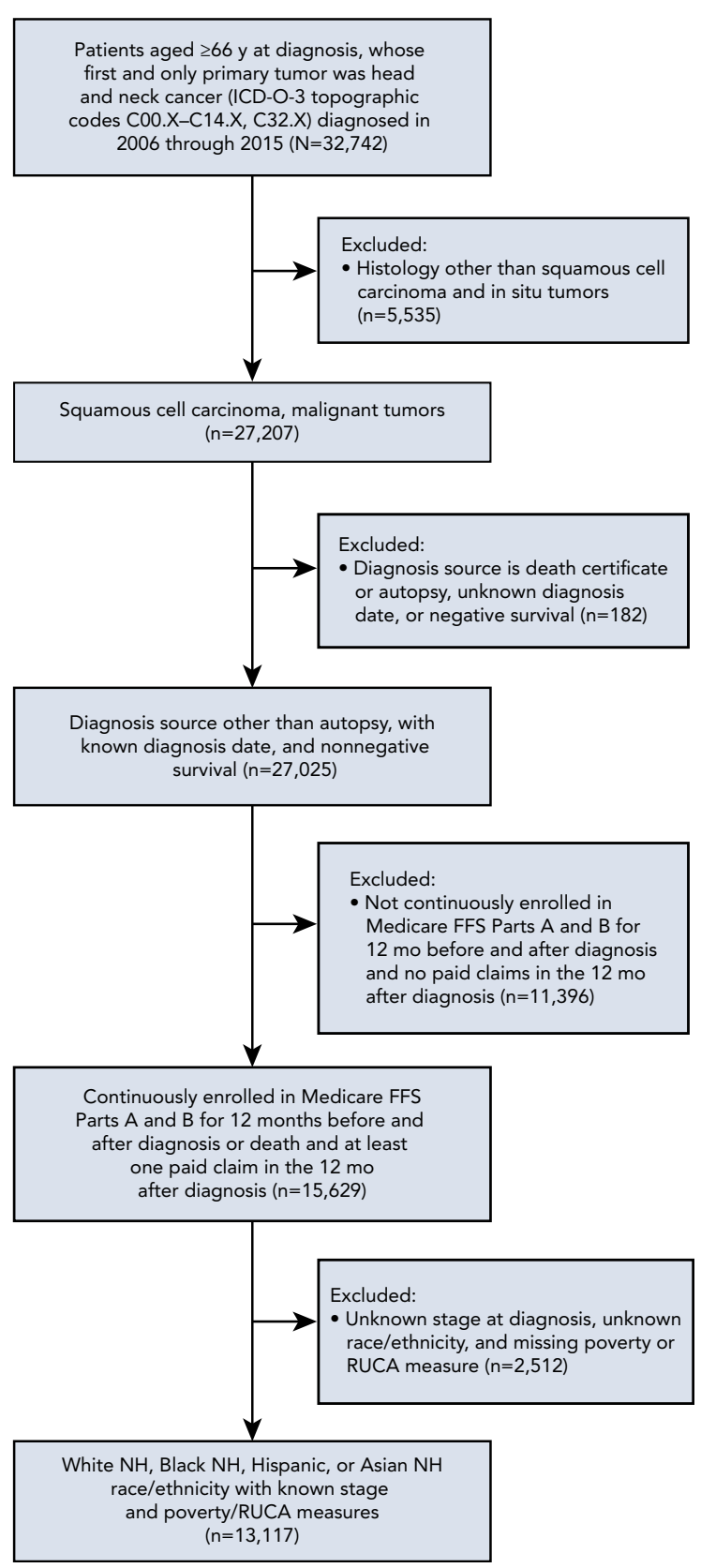

Figure 1. Sample derivation.

Abbreviations: FFS, fee-for-service; NH, non-Hispanic; RUCA, rural-urban commuting area.

Medicare claims identified healthcare use in the year before diagnosis. ${ }^{17,18}$ Visits to a primary care provider (PCP) included visits to the specialties of general practice, family practice, internal medicine, and geriatric medicine; a multispecialty clinic; or a group practice. Visits to an otolaryngology (ENT) specialist and the emergency department (ED) were documented.

Medicare claims identified whether a patient had visited an NCI-designated cancer center or teaching 
hospital 2 months before diagnosis through 6 months after diagnosis. Receipt of PET imaging after diagnosis was recorded.

\section{Medical Care Spending}

We estimated the average spending per patient on treatment using the amount paid by Medicare for cancer- and treatment-related institutional and noninstitutional claims. ${ }^{19,20}$ Total spending was estimated by adding patient copayments and deductibles to the Medicare claims.

\section{Statistical Analysis}

Chi-square tests assessed univariate associations with binary outcomes, including late versus early cancer stage at diagnosis and receipt versus no receipt of treatment. Multivariate logistic regression examined multivariate associations for these outcomes. Means and standard deviations were calculated for number of healthcare visits, healthcare spending, and time to treatment.

The Kaplan-Meier method and unadjusted Cox proportional hazards were used for univariate survival analyses. Multivariate survival analyses used Cox proportional hazards models, adjusting for covariates. A forward stepwise analysis used 4 different models to examine the effects of controlling for covariates of interest on the hazard ratios (HRs) comparing racial/ethnic groups. The base model controlled for demographic and tumor factors. The second model added socioeconomic status variables (RUCA, poverty, and hospital type). The third model added stage at diagnosis, and the fourth model added treatment.

SAS 9.4 (SAS Institute Inc.) was used for all analyses. Significance was evaluated at $P<.05$.

\section{Results}

\section{Descriptive Statistics}

Table 1 and supplemental eTable 1 (available with this article atJNCCN.org) list the characteristics of 13,117 patients who met the selection criteria according to race/ethnicity. The sample comprised 10,858 (82.8\%) White NH, 994 (7.6\%) Black NH, 725 (5.5\%) Hispanic, and 540 (4.1\%) Asian NH individuals. The Black NH patient group included the highest percentage of patients living in high-poverty areas (58.5\%) and with a comorbidity score $\geq 2(36.9 \%)$. Only $39.0 \%$ of Hispanic patients lived in high-poverty areas, and $31.3 \%$ had a comorbidity score $\geq 2$. Black NH patients were least likely to be married $(30.7 \%$ vs $49.7 \%$ of Hispanic patients), and also had the highest percentage of AJCC stage IV cancers (50.4\%). Black NH and Hispanic patients both had the lowest frequency of PCP $(76.2 \%$ and $75.6 \%$, respectively) and ENT visits $(36.2 \%$ and $37.9 \%$, respectively), but Black NH patients had the highest percentage of ED visits in the year before diagnosis $(45.0 \%)$. Black NH patients were least likely to receive cancer-directed therapy, with only $80.8 \%$ receiving such treatment.

\section{Black NH Patients Have Worst Survival Outcomes}

Black NH patients had the worst OS (HR of death, 1.47; 95\% CI, 1.35-1.60) and CSS (HR, 1.48; 95\% CI, 1.33-1.65) (Figure 2). Hispanic patients had survival rates similar to those of White $\mathrm{NH}$ and Asian NH patients (OS: HR of death, 1.03; 95\% CI, 0.92-1.15; CSS: HR, 1.12; 95\% CI, 0.99-1.28). Given that survival outcomes for Hispanic patients, another historically underrepresented group in the United States, did not show a significant difference from those of White $\mathrm{NH}$ patients, we performed a forward stepwise Cox regression analysis to explore the effects of several variables on CSS (Table 2). CSS was significantly worse for Black NH patients than for Hispanic patients in the base model adjusting for sex, age, marital status, geographic region, comorbidity score, and primary site of disease (HR, 1.43; 95\% CI, 1.16-1.76). Stepwise analysis identified the addition of AJCC stage and receipt of cancer treatment as significant factors to explain the survival differences between these cohorts. Each stage greater than stage I had an increasing risk of death, and each treatment modality had a decreased risk of death compared with no treatment. Accounting for these covariates in the final model resulted in a similar CSS in Black $\mathrm{NH}$ patients compared with Hispanic patients (HR, 1.14; 95\% CI, 0.92-1.41). OS had a similar trend, with the base model showing a significant difference in OS in Black NH patients compared with Hispanic patients (HR, 1.45; 95\% CI, 1.22-1.73), explained by stage and receipt of treatment. These findings were comparable in the CSS (supplemental eTable 2) and OS models including all racial/ethnic cohorts.

\section{Socioeconomic Factors and Healthcare Use Predict Stage of Diagnosis}

Black $\mathrm{NH}$ patients were more likely to be diagnosed at AJCC stage III/IV (odds ratio [OR] 1.62; 95\% CI, 1.38-1.90). Because stage was a significant contributor to CSS and OS in Black NH patients, we sought to find predictors of late stage at diagnosis (Figure 3). Unmarried/Unpartnered patients were more likely to have a later stage (OR, 1.27; 95\% CI, 1.17-1.37) as were those living in areas with $\geq 20 \%$ of the population living below the poverty level (OR, 1.12; 95\% CI, 1.01-1.23). Visits with a PCP or ENT over the past year decreased the likelihood of presenting with stage III/IV disease (PCP: OR, 0.73; 95\% CI, 0.67-0.82; ENT: OR, 0.59; 95\% CI, 


\begin{tabular}{|c|c|c|c|}
\hline Characteristic & $\begin{array}{c}\text { Black NH } \\
\text { (\%) }\end{array}$ & $\begin{array}{c}\text { Hispanic } \\
\text { (\%) }\end{array}$ & $\begin{array}{c}P \\
\text { Value }^{a}\end{array}$ \\
\hline Patients, $\mathrm{n}$ & 994 & 725 & \\
\hline Sex & & & .973 \\
\hline Female & 27.0 & 27.0 & \\
\hline Male & 73.0 & 73.0 & \\
\hline Age, y & & & $<.001$ \\
\hline $66-74$ & 63.9 & 53.1 & \\
\hline $75-84$ & 28.6 & 34.8 & \\
\hline$\geq 85$ & 7.5 & 12.1 & \\
\hline Marital status & & & $<.001$ \\
\hline Unmarried & 69.3 & 50.3 & \\
\hline Married/Partnered & 30.7 & 49.7 & \\
\hline Registry region & & & $<.001$ \\
\hline East & 18.0 & 16.1 & \\
\hline Midwest & 15.9 & 1.8 & \\
\hline South & 47.2 & 4.0 & \\
\hline West & 18.9 & 78.1 & \\
\hline Patient urban/rural recode category & & & .054 \\
\hline Urban commuting area & 93.2 & 90.6 & \\
\hline Nonurban commuting area & 6.8 & 9.4 & \\
\hline Census tract percentage below pove & ty level & & $<.001$ \\
\hline$<20 \%$ & 41.4 & 61.0 & \\
\hline$\geq 20 \%$ & 58.5 & 39.0 & \\
\hline Visited $\mathrm{NCl}$-designated $\mathrm{CC}$ or teachi & g hospital & & $<.001$ \\
\hline No or unknown & 19.4 & 26.6 & \\
\hline $\mathrm{NCl}$-designated CC & 14.6 & 24.4 & \\
\hline Teaching hospital & 66.0 & 49.0 & \\
\hline Charlson comorbidity score & & & $<.001$ \\
\hline 0 & 37.3 & 44.4 & \\
\hline 1 & 25.7 & 24.3 & \\
\hline$\geq 2$ & 36.9 & 31.3 & \\
\hline Primary site & & & $<.001$ \\
\hline Lip and oral cavity & 14.1 & 27.6 & \\
\hline Oropharynx & 23.6 & 19.2 & \\
\hline Nasopharynx & 3.1 & 2.3 & \\
\hline Hypopharynx & 7.1 & 5.7 & \\
\hline Larynx & 47.0 & 35.6 & \\
\hline Salivary glands/overlapping/NOS & 5.0 & 9.7 & \\
\hline AJCC cancer stage & & & $<.001$ \\
\hline I & 17.4 & 23.7 & \\
\hline II & 13.6 & 16.0 & \\
\hline III & 18.6 & 19.2 & \\
\hline IVA, IVB, or IV NOS & 43.4 & 35.6 & \\
\hline IVC & 7.0 & 5.5 & \\
\hline
\end{tabular}

(continued)

\begin{tabular}{|c|c|c|c|}
\hline Characteristic & $\begin{array}{c}\text { Black NH } \\
(\%)\end{array}$ & $\begin{array}{c}\text { Hispanic } \\
(\%)\end{array}$ & $\begin{array}{c}P \\
\text { Value }^{\mathbf{a}}\end{array}$ \\
\hline Receipt of any treatment within $6 \mathrm{~m}$ & & & .002 \\
\hline No & 19.2 & 13.7 & \\
\hline Yes & 80.8 & 86.3 & \\
\hline Any visits with $\mathrm{PCP}$ in prior year & & & .785 \\
\hline No & 23.8 & 24.4 & \\
\hline Yes & 76.2 & 75.6 & \\
\hline Any visits with otolaryngology in pric & year & & .467 \\
\hline No & 63.8 & 62.1 & \\
\hline Yes & 36.2 & 37.9 & \\
\hline Any ED visits in prior year & & & $<.001$ \\
\hline No & 55.0 & 66.5 & \\
\hline Yes & 45.0 & 33.5 & \\
\hline
\end{tabular}

Statistics are unweighted column percentages.

Abbreviations: $C C$, cancer center; $E D$, emergency department;

$\mathrm{NH}$, non-Hispanic; NOS, not otherwise specified; PCP, primary care physician. aBold indicates statistically significant $P$ value.

0.54-0.64), whereas ED visits increased the likelihood (OR, 1.21; 95\% CI, 1.10-1.32).

The average number of visits to each type of provider (PCP, ENT, or ED) in the year before diagnosis was calculated, because healthcare visits were an important predictor of cancer stage at diagnosis (Figure 4). The mean number of ENT visits (Black NH patients, $0.80 \pm$ 1.58; Hispanic patients, $0.85 \pm 1.55$ ) and PCP visits (Black $\mathrm{NH}$ patients, $4.89 \pm 5.72$; Hispanic patients, $4.86 \pm 5.24$ ) were not significantly different. Conversely, ED visits were significantly higher among Black $\mathrm{NH}$ patients, with an average of $1.033 \pm 1.92$ visits in the year before diagnosis compared with $0.76 \pm 1.59$ visits for Hispanic patients.

\section{Predictors of Receipt of Treatment}

Logistic regression revealed that Black $\mathrm{NH}$ patients were less likely to receive any treatment for their squamous cell HNC, including chemotherapy, RT, and surgery, compared with Hispanic patients (OR, 0.46 ; 95\% CI, 0.32-0.65) (Table 3). At least one visit to an NCI-designated cancer center (OR, 1.77; 95\% CI, $1.17-2.70$ ) or teaching hospital (OR, 2.28; 95\% CI, 1.65-3.16) increased receipt of treatment. Patients who underwent a PET scan were also more likely to receive cancer treatment (OR, 2.37; 95\% CI, 1.78-3.17). Higher cancer stages predicted lower likelihood of treatment (stage IVA, B, or not otherwise specified: OR, 0.66; 95\% CI, 0.44-0.99; stage IVC: OR, 0.33; 95\% CI, 0.19-0.58). Mean days from diagnosis until start of treatment were not significantly different between Black 
A

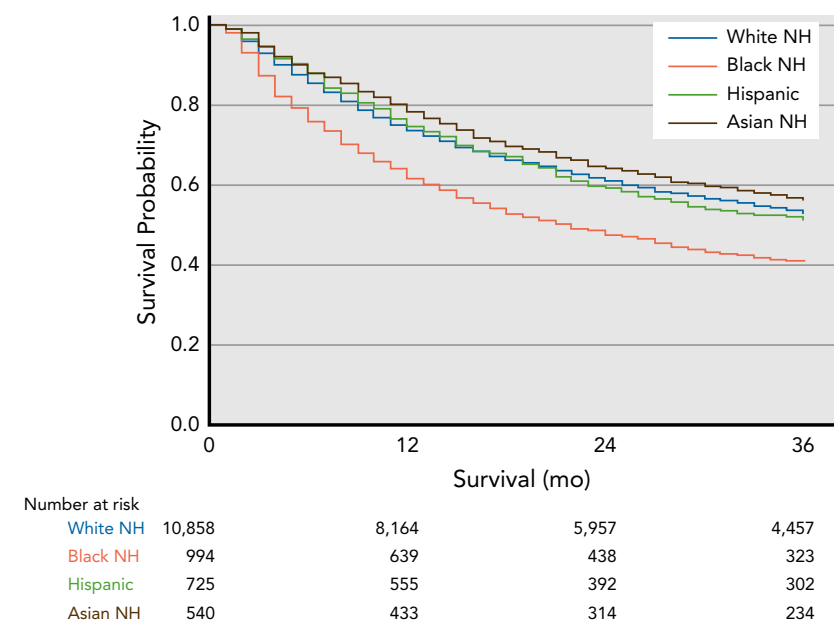

B

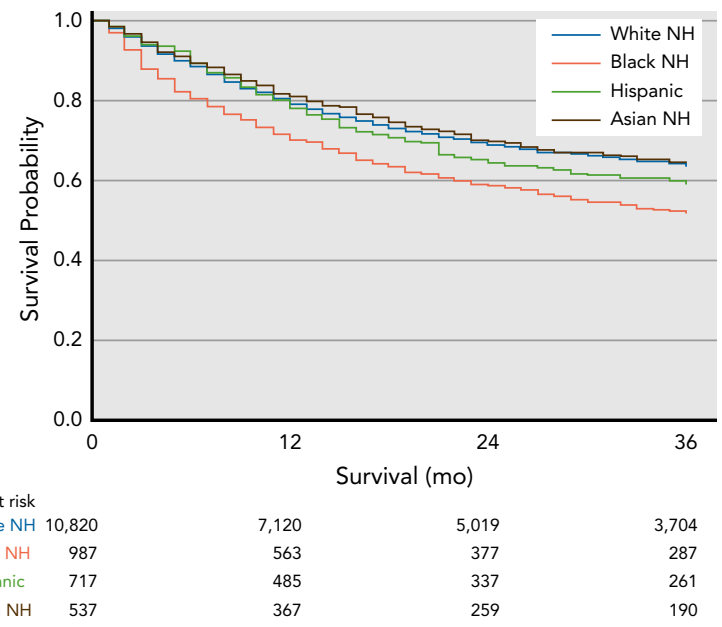

Figure 2. (A) Overall and (B) cancer-specific survival in patients with squamous cell head and neck cancer, by race/ethnicity. Abbreviation: $\mathrm{NH}$, non-Hispanic.

NH $(31.7 \pm 27.3)$ and Hispanic patients $(31.1 \pm 29.0$; $P=.781)$.

\section{Treatment Spending Similar Between Groups}

Mean total Medicare payments on treatment claims for Black NH patients who received any treatment were $\$ 29,765 \pm \$ 31,084$. This was not significantly different from Hispanic patients, with mean payments of $\$ 31,050$ $\pm \$ 28,989$. Conversely, White NH patients had lower mean payments at $\$ 25,848 \pm \$ 26,614$. The distributions of payments remained similar when divided by treatment types.

\section{Discussion}

In 1985, the Heckler $^{21}$ report provided the first comprehensive study of healthcare disparities experienced by Black and other minority individuals in the United States, calling it an "affront both to our ideals and to the ongoing genius of American medicine." More than 30 years later, such disparities persist. In this updated SEER-Medicare analysis, Black NH race continues to function as a critical risk factor for worst CSS outcomes in HNC. We identified late cancer stage at diagnosis and receipt of any treatment as areas of major health gaps accounting for disparities between Black NH individuals and those of other races/ethnicities.

Although other studies have shown that Black NH patients have worse survival outcomes in $\mathrm{HNC}^{8-15}$ our data underscore that this holds true compared with Hispanic patients, a similarly underserved population. Hispanic patients were more likely to present with an earlier cancer stage and to receive treatment. Black $\mathrm{NH}$ patients continued to have a higher risk of overall and cancer-specific mortality, even after adjustment for patient characteristics. Despite a higher percentage of Black NH individuals living in higher-poverty and urban areas, adjusting for these socioeconomic factors did not change their higher risk of mortality. It was not until we adjusted for stage and receipt of treatment that the mortality differences became comparable. Although others have found that, after adjusting for other variables, insurance coverage had the most significant effect on survival in Black patients, ${ }^{10,13,22,23}$ we included only Medicare recipients. This suggests that there are factors in addition to insurance that constitute barriers to access to care and receipt of treatment in Black NH patients with HNC.

Black NH and Hispanic individuals typically have similarities in lower socioeconomic status and high comorbid illnesses ${ }^{24,25}$; however, Black $\mathrm{NH}$ patients had worse CSS outcomes. Therefore, we sought to establish modifiable potential predictors of stage presentation. Black NH individuals were more likely to live in areas of high poverty and to be unmarried. They also had more ED visits before diagnosis. These data indicate 2 major correlates driving poor cancer-specific outcomes in Black NH patients: poverty and lack of social support, and decreased receipt of ideal medical care.

Poverty is a prime predictor of greater cancer burden and is highly correlated with poor health outcomes. ${ }^{26}$ Black NH individuals are the poorest ethnic group in the United States, with the lowest median household income for the past 50 years. ${ }^{27}$ Lower social support, including marriage, is another hallmark of poverty and is a significant predictor of poor outcomes in HNC. ${ }^{28-30}$ Poverty is associated with cancer risk factors such as tobacco use, obesity, and lack of access to cancer screening and treatment. Although not recorded in the SEER-Medicare database, tobacco use is associated with laryngeal, oral 
Table 2. Effects of Individual Covariates on Cancer-Specific Survival Differences in Black Non-Hispanic Versus Hispanic Patients

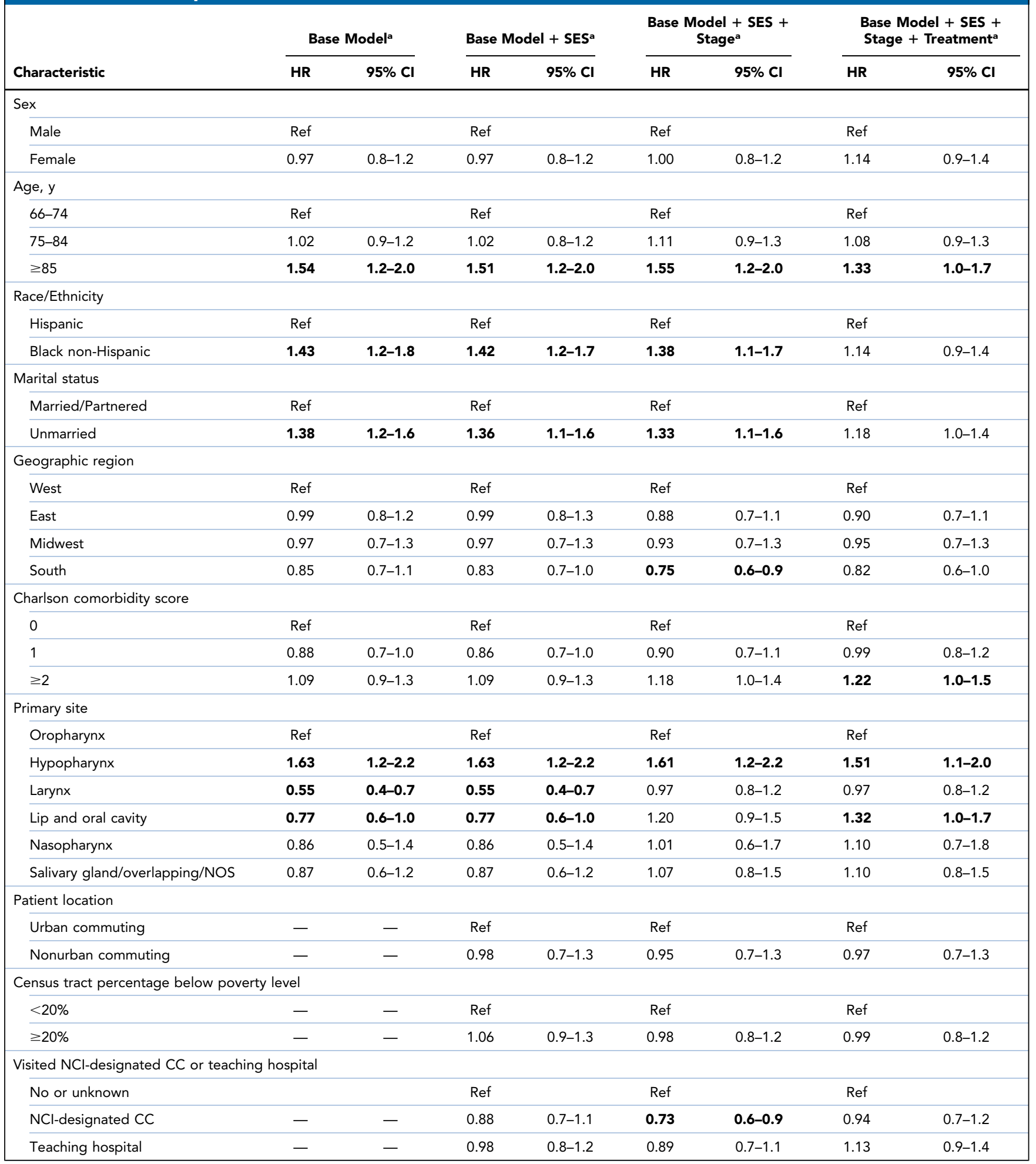




\begin{tabular}{|c|c|c|c|c|c|c|c|c|}
\hline \multirow[b]{2}{*}{ Characteristic } & \multicolumn{2}{|c|}{ Base Modela } & \multicolumn{2}{|c|}{ Base Model + SES } & \multicolumn{2}{|c|}{$\underset{\text { Stage }^{\mathbf{a}}}{\text { Base Model + SES + }}$} & \multicolumn{2}{|c|}{$\begin{array}{c}\text { Base Model + SES + } \\
\text { Stage + Treatment }\end{array}$} \\
\hline & HR & $95 \% \mathrm{Cl}$ & HR & $95 \% \mathrm{Cl}$ & HR & $95 \% \mathrm{Cl}$ & HR & $95 \% \mathrm{Cl}$ \\
\hline \multicolumn{9}{|l|}{ AJCC cancer stage } \\
\hline I & - & - & - & - & Ref & & Ref & \\
\hline ॥ & - & - & - & - & 1.96 & $1.3-3.0$ & 1.80 & $1.2-2.8$ \\
\hline III & - & - & - & - & 4.40 & $3.0-6.4$ & 4.77 & $3.3-7.0$ \\
\hline IVA, IVB, or IV NOS & - & - & - & - & 7.11 & $5.0-10.1$ & 7.39 & $5.1-10.7$ \\
\hline IVC & - & - & - & - & 15.53 & $10.3-23.4$ & 13.05 & $8.4-20.2$ \\
\hline \multicolumn{9}{|l|}{ Treatment } \\
\hline None & - & - & - & - & - & - & Ref & \\
\hline Chemotherapy alone & - & - & - & - & - & - & 0.47 & $0.3-0.8$ \\
\hline RT + chemotherapy & - & - & - & - & - & - & 0.28 & $0.2-0.4$ \\
\hline RT alone & - & - & - & - & - & - & 0.45 & $0.3-0.6$ \\
\hline Surgery + chemotherapy & - & - & - & - & - & - & 0.45 & $0.2-1.1$ \\
\hline Surgery + RT & - & - & - & - & - & - & 0.22 & $0.2-0.3$ \\
\hline Surgery + RT + chemotherapy & - & - & - & - & - & - & 0.21 & $0.2-0.3$ \\
\hline Surgery alone & - & - & - & - & - & - & 0.25 & $0.2-0.4$ \\
\hline
\end{tabular}

Year of diagnosis was included in the analysis but excluded from the table.

Abbreviations: CC, cancer center; HR, hazard ratio; NOS, not otherwise specified; RT, radiation therapy; SES, socioeconomic status.

aBold indicates statistically significant values.

cavity, and pharyngeal cancers, ${ }^{31}$ which were the most common primary sites of disease in Black $\mathrm{NH}$ patients in our study.

There is minimal evidence on the role of primary and specialty care use and outcomes in HNC. Black NH patients had similar numbers of PCP visits as Hispanic patients, although both were lower compared with White $\mathrm{NH}$ patients. In the United States, available evidence suggesting that primary and preventive care reduces cancer mortality rates comes from breast and colon

\begin{tabular}{|c|c|c|c|c|c|}
\hline Predictor & & & $\begin{array}{l}\text { Odds } \\
\text { Ratio }\end{array}$ & $95 \% \mathrm{Cl}$ & $P$ Value \\
\hline \multicolumn{6}{|c|}{ Race/Ethnicity (Ref = White NH) } \\
\hline Asian $\mathrm{NH}$ & $\mapsto$ & $+\infty$ & 1.12 & $(0.91-1.36)$ & .2827 \\
\hline Black NH & & $\longmapsto$ & 1.62 & $(1.38-1.90)$ & $<.0001$ \\
\hline Hispanic & & $\mapsto-1$ & 1.24 & $(1.04-1.47)$ & .0150 \\
\hline \multicolumn{6}{|c|}{ Marital status $($ Ref $=$ married $/$ partnered $)$} \\
\hline Nonmarried & & $\vdash-1$ & 1.27 & $(1.17-1.37)$ & $<.0001$ \\
\hline \multicolumn{6}{|c|}{ Census tract percentage below poverty level (Ref $=<20 \%)$} \\
\hline$\geq 20 \%$ & & $1 \bullet-1$ & 1.12 & $(1.01-1.23)$ & .0300 \\
\hline \multicolumn{6}{|c|}{ Charlson comorbidity index $(\operatorname{Ref}=0)$} \\
\hline 1 & & +-1 & 1.05 & $(0.96-1.16)$ & .2903 \\
\hline$\geq 2$ & & $+\forall$ & 1.07 & $(0.97-1.18)$ & .1794 \\
\hline \multicolumn{6}{|c|}{ Any prior PCP visits $(\operatorname{Ref}=$ no $)$} \\
\hline Yes & $\mapsto-1$ & & 0.74 & $(0.66-0.82)$ & $<.0001$ \\
\hline \multicolumn{6}{|c|}{ Any prior otolaryngology visits (Ref $=$ no) } \\
\hline Yes & $\vdash-1$ & & 0.59 & $(0.54-0.64)$ & $<.0001$ \\
\hline \multicolumn{6}{|c|}{ Any prior ED visits $(\operatorname{Ref}=$ no) } \\
\hline \multirow[t]{2}{*}{ Yes } & & $\mapsto-1$ & 1.21 & $(1.11-1.32)$ & $<.0001$ \\
\hline & Late stage less likely & Late stage more & likely & & \\
\hline
\end{tabular}

Figure 3. Multivariate regression, controlling for demographic and tumor characteristics, for predicting late stage at diagnosis. Abbreviations: $E D$, emergency department; $\mathrm{NH}$, non-Hispanic; $\mathrm{PCP}$, primary care provider. 
A

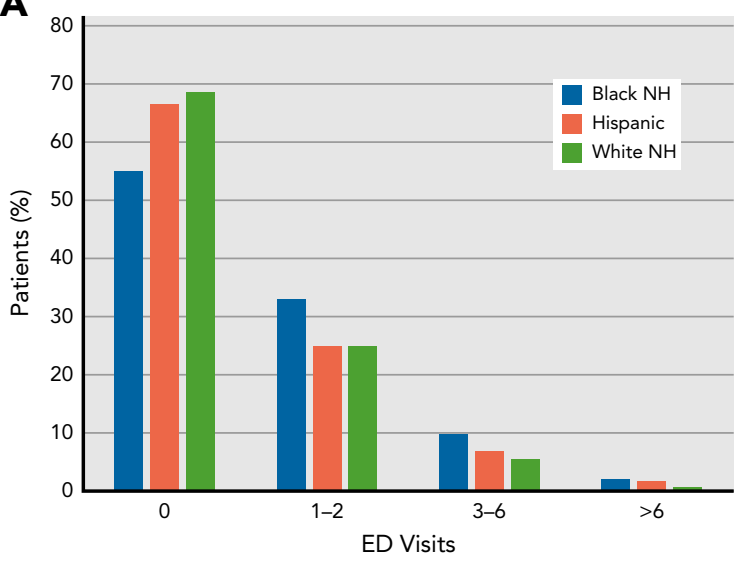

B

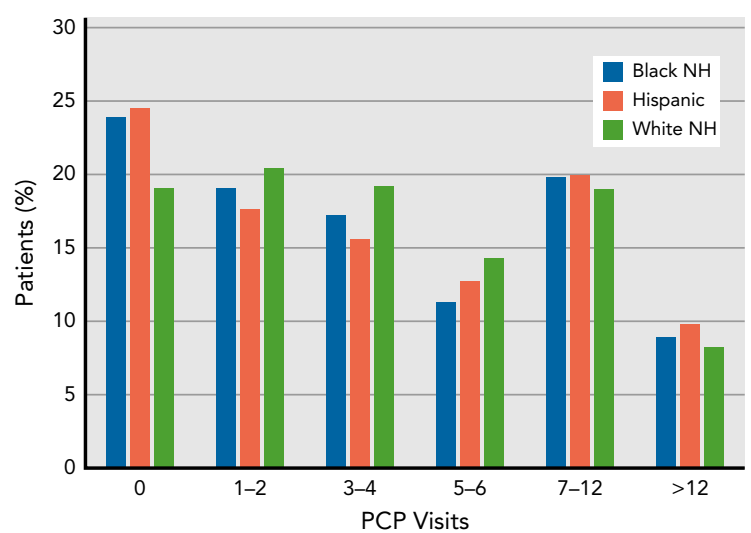

Figure 4. Distribution of (A) ED and (B) PCP visits in different racial/ethnic cohorts. Abbreviations: $E D$, emergency department; $\mathrm{NH}$, non-Hispanic; $\mathrm{PCP}$, primary care provider.

cancer, for which screening guidelines are available..$^{32,33}$ An important role of primary care when considering smoking-related cancers is smoking cessation, but studies have shown that Black $\mathrm{NH}$ individuals are less likely to engage in smoking cessation programs or to quit smoking in these programs. ${ }^{34,35}$ There are no data that we are aware of describing ED use and cancer stage at presentation, but it is well-documented that frequent users of EDs have increased overall mortality rates, more comorbid conditions, and lower health literacy. ${ }^{36,37}$ The Black NH patients in our study were more likely than Hispanic patients to have ED visits. Nationally, Black NH individuals are more likely to use the ED as a usual source of care and are only two-thirds as likely to see a PCP. ${ }^{38,39}$ Although these statistics have improved with the Affordable Care Act, ${ }^{40}$ this highlights the importance of increasing education, trust, and access to care among Black patients in order to increase PCP use.

Payment for cancer treatment-related care was similar between Black $\mathrm{NH}$ and Hispanic patients but higher than for White $\mathrm{NH}$ patients. This may correspond to the presence of advanced disease on presentation, which is associated with increasing costs. ${ }^{41}$ This finding is similar to prior data showing that Black patients accumulated more in costs for HNC than White patients, ${ }^{42}$ and further corroborates that healthcare spending in the preventive and early diagnosis stages will improve outcomes and ultimately decrease overall spending.

Although we found that receiving cancer-directed treatment of any kind improved outcomes, Black NH patients were less likely to receive treatment even when we adjusted for characteristics including age, cancer stage and primary site, socioeconomic status, and comorbid conditions. Although it is impossible to assess what treatment options were offered or declined, it has previously been described that Black patients are less likely than others to undergo surgery for HNC. ${ }^{10,15,43}$ There are many data showing mistrust of the medical community among Black patients, ${ }^{44,45}$ in addition to the role of implicit bias and structural racism in the community ${ }^{46}$ all of which can be associated with delayed or forgone medical care or refusal of ideal medical care. It is imperative for healthcare workers to educate themselves on racism and cultural differences and to form trusting relationships with their patients to provide optimal cancer care.

Patients were more likely to undergo treatment if they received services at an NCI-designated cancer center or teaching hospital. Studies have shown that individuals in minority groups are less likely than others to receive treatment at high-volume hospitals and NCI-designated centers ${ }^{47,48}$; however, these facilities are associated with increased HNC survival outcomes, particularly between different racial/ethnic groups. ${ }^{49,50}$ Due to the complexity of HNC treatment, it is important for patients and physicians to consider referral for treatment at or at least treatment recommendations from a tertiary cancer center.

Although there is much ongoing research addressing health disparities in underserved populations, several solutions could improve outcomes in Black NH patients. Diversifying the healthcare workforce to allow better racial/ethnic and cultural understanding can decrease communication barriers and improve patient retention and compliance with treatments. ${ }^{51}$ Increased use of patient navigation programs can help patients maneuver complex issues that prevent ideal care, including financial and social issues, follow-up appointments, and education. ${ }^{52}$ Finally, disparities can be reduced by challenging healthcare systems to focus on racial/ethnic inequalities through initiatives such as implicit bias 


\begin{tabular}{|c|c|c|c|}
\hline Characteristic & $\begin{array}{l}\text { Odds } \\
\text { Ratio }\end{array}$ & $95 \% \mathrm{Cl}$ & P Value ${ }^{b}$ \\
\hline \multicolumn{3}{|l|}{ Race } & $<.001$ \\
\hline Hispanic & Ref & & \\
\hline Black non-Hispanic & 0.46 & $0.32-0.65$ & \\
\hline \multicolumn{3}{|l|}{ Sex } & .011 \\
\hline Male & Ref & & \\
\hline Female & 1.58 & $1.12-2.25$ & \\
\hline \multicolumn{3}{|l|}{ Age, y } & .086 \\
\hline $66-74$ & Ref & & \\
\hline $75-84$ & 0.85 & $0.63-1.15$ & \\
\hline$\geq 85$ & 0.60 & $0.60-0.38$ & \\
\hline \multicolumn{3}{|l|}{ Marital status } & .435 \\
\hline Married/Partnered & Ref & & \\
\hline Unmarried & 0.89 & $0.66-1.19$ & \\
\hline \multicolumn{3}{|l|}{ Registry region } & .027 \\
\hline West & Ref & & \\
\hline East & 1.44 & $0.93-2.22$ & \\
\hline Midwest & 1.02 & $0.60-1.72$ & \\
\hline South & 1.73 & $1.15-2.55$ & \\
\hline \multicolumn{3}{|c|}{ Patient urban/rural recode category } & .196 \\
\hline Urban commuting area & Ref & & \\
\hline Nonurban commuting area & 1.45 & $0.82-2.54$ & \\
\hline \multicolumn{3}{|c|}{ Census tract percentage below poverty level } & .549 \\
\hline$<20 \%$ & Ref & & \\
\hline$\geq 20 \%$ & 1.09 & $0.82-1.45$ & \\
\hline \multicolumn{3}{|c|}{ Visited $\mathrm{NCl}$-designated $\mathrm{CC}$ or teaching hospital } & $<.001$ \\
\hline No or unknown & Ref & & \\
\hline $\mathrm{NCl}$-designated $\mathrm{CC}$ & 1.77 & $1.17-2.70$ & \\
\hline Teaching hospital & 2.28 & $1.65-3.16$ & \\
\hline \multicolumn{3}{|l|}{ Charlson comorbidity score } & .016 \\
\hline 0 & Ref & & \\
\hline 1 & 1.73 & $1.19-2.51$ & \\
\hline$\geq 2$ & 1.16 & $0.86-1.58$ & \\
\hline \multicolumn{3}{|l|}{ Primary site } & .006 \\
\hline Oropharynx & Ref & & \\
\hline Hypopharynx & 0.47 & $0.27-0.80$ & \\
\hline Larynx & 0.75 & $0.52-1.10$ & \\
\hline Lip and oral cavity & 1.13 & $0.70-1.80$ & \\
\hline Nasopharynx & 0.57 & $0.26-1.26$ & \\
\hline $\begin{array}{l}\text { Salivary glands/overlapping/ } \\
\text { NOS }\end{array}$ & 1.64 & $0.80-3.35$ & \\
\hline
\end{tabular}

(continued)

\begin{tabular}{|c|c|c|c|}
\hline Characteristic & $\begin{array}{l}\text { Odds } \\
\text { Ratio }\end{array}$ & $95 \% \mathrm{Cl}$ & $P$ Value $^{\mathrm{b}}$ \\
\hline AJCC cancer stage & & & $<.001$ \\
\hline I & Ref & & \\
\hline ॥ & 1.00 & $0.61-1.62$ & \\
\hline III & 1.09 & $0.69-1.74$ & \\
\hline IVA, IVB, or IV NOS & 0.66 & $0.44-0.99$ & \\
\hline IVC & 0.33 & $0.19-0.58$ & \\
\hline
\end{tabular}

Abbreviations: CC, cancer center; NOS, not otherwise specified. aOdds ratios are calculated as likelihood to receive treatment. ${ }^{b} B o l d$ indicates statistically significant $P$ value.

training, increased disparity research, and allocation of funding for programs that increase access to care for underserved populations. ${ }^{53}$

This study has limitations inherent in the use of the SEER-Medicare registry. Our population was limited to patients enrolled in Medicare fee-for-service plans, which excludes younger patients and those receiving other insurance/medical coverage. Age has not previously been described to impact racial disparities, but socioeconomic status may, and patients in the SEER-Medicare database have been described to be at an economic disadvantage. ${ }^{54}$ Receipt of treatment is a significant prognostic factor in our findings, but we cannot distinguish reasons why treatment was not offered or accepted, which may introduce bias. Furthermore, SEER-Medicare does not provide HPV data. HPV-related oropharyngeal cancer has a lower incidence in Black Americans and may have a significant impact on the survival differences. ${ }^{6,12,55}$ Finally, the SEER registry does not have accurate tobacco use data, although prior studies that have stratified patients by smoking habits showed no impact on disparaties. ${ }^{10,11,24}$

\section{Conclusions}

This analysis provides further evidence of the disparities in survival outcomes in $\mathrm{HNC}$ among Black NH patients compared with all other racial/ethnic cohorts, including Hispanic patients, another underserved ethnic minority. Our findings showed that Black NH patients present with later stage at diagnosis and receive less treatment after diagnosis. Efforts should be made to address modifiable factors that lead to these higher cancer stages, including improving access to nonemergent healthcare; enhancing prevention and screening programs, including tobacco cessation; and increasing navigational support. Once patients are diagnosed, efforts to increase trust, decrease 
bias and racism, and provide access to multidisciplinary/ tertiary cancer care should be prioritized to bridge the treatment gap for Black NH individuals.

Submitted March 27, 2020; accepted for publication June 22, 2020.

Published online September 28, 2020.

Author contributions: Study concept: McDermott, Karam. Data acquisition: Borrayo, Karam. Data analysis and interpretation: McDermott, Eguchi, Karam. Project supervision: Borrayo. Manuscript preparation: McDermott. Critical revision: All authors.

Disclosures: The authors have disclosed that they have not received any financial consideration from any person or organization to support the preparation, analysis, results, or discussion of this article.
Funding: Research reported in this publication was supported by the Population Health Shared Resource, University of Colorado Cancer Center (NC award P30CA046934). Dr. Karam is supported by the National Institute of Dental and Craniofacial Research of the NIH (R01 DE028529-01 and R01 DE028282-01), and receives clinical trial funding from the Cancer League of Colorado and from AstraZeneca for work unrelated to this research.

Disclaimer: The content is solely the responsibility of the authors and does not necessarily represent the official views of the $\mathrm{NIH}$. None of the funders had any role in the conduct of the study; in the collection, management, analysis, or interpretation of the data; or in the preparation, review, or approval of the manuscript.

Correspondence: Jessica D. McDermott, MD, University of Colorado Cancer Center, Department of Medical Oncology, 1665 Aurora Court, Aurora, CO 80045. Email: jessica.mcdermott@cuanschutz.edu; and

Sana D. Karam, MD, PhD, University of Colorado Anschutz School of Medicine, Department of Radiation Oncology, 1665 Aurora Court, Aurora, CO 80045. Email: sana.karam@cuanschutz.edu

\section{References}

1. American Cancer Society. Cancer Facts \& Figures 2018. Accessed August 1, 2019. Available at: https://www.cancer.org/content/dam/cancer-org/ research/cancer-facts-and-statistics/annual-cancer-facts-and-figures/ 2018/cancer-facts-and-figures-2018.pdf

2. DeSantis C, Naishadham D, Jemal A. Cancer statistics for African Americans, 2013. CA Cancer J Clin 2013;63:151-166.

3. Ferlay J, Soerjomataram I, Dikshit R, et al. Cancer incidence and mortality worldwide: sources, methods and major patterns in GLOBOCAN 2012. Int J Cancer 2015;136:E359-386.

4. Goodwin WJ, Thomas GR, Parker DF, et al. Unequal burden of head and neck cancer in the United States. Head Neck 2008;30:358-371.

5. Settle K, Posner MR, Schumaker LM, et al. Racial survival disparity in head and neck cancer results from low prevalence of human papillomavirus infection in black oropharyngeal cancer patients. Cancer Prev Res (Phila) 2009;2:776-781.

6. Lenze NR, Farquhar DR, Mazul AL, et al. Racial disparities and human papillomavirus status in oropharyngeal cancer: a systematic review and meta-analysis. Head Neck 2019;41:256-261.

7. Howlader N, Noone AM, Krapcho M, et al, eds. SEER Cancer Statistics Review, 1975-2014, National Cancer Institute. Bethesda, MD. Based on November 2016 SEER data submission, posted to the SEER web site, April 2017. Accessed August 1, 2019. Available at: http://seer.cancer.gov/csr/ 1975_2014/

8. Hoffman HT, Karnell LH, Funk GF, et al. The National Cancer Data Base report on cancer of the head and neck. Arch Otolaryngol Head Neck Surg 1998; 124:951-962.

9. Shavers VL, Harlan LC, Winn D, et al. Racial/ethnic patterns of care for cancers of the oral cavity, pharynx, larynx, sinuses, and salivary glands. Cancer Metastasis Rev 2003;22:25-38.

10. Gourin CG, Podolsky RH. Racial disparities in patients with head and neck squamous cell carcinoma. Laryngoscope 2006;116:1093-1106.

11. Nichols AC, Bhattacharyya N. Racial differences in stage and survival in head and neck squamous cell carcinoma. Laryngoscope 2007;117: 770-775.

12. Peterson CE, Khosla S, Chen LF, et al. Racial differences in head and neck squamous cell carcinomas among non-Hispanic black and white males identified through the National Cancer Database (1998-2012). J Cancer Res Clin Oncol 2016;142:1715-1726.

13. Albert A, Giri S, Kanakamedala M, et al. Racial disparities in tumor features and outcomes of patients with squamous cell carcinoma of the tonsil. Laryngoscope 2019;129:643-654.

14. Megwalu UC, Ma Y. Racial disparities in oropharyngeal cancer survival. Oral Oncol 2017;65:33-37

15. Du XL, Liu CC. Racial/ethnic disparities in socioeconomic status, diagnosis, treatment and survival among Medicare-insured men and women with head and neck cancer. J Health Care Poor Underserved 2010; 21:913-930.

16. National Cancer Institute. SEER-Medicare: Brief Description of the SEERMedicare Database. Accessed August 2019. Available at: https:// healthcaredelivery.cancer.gov/seermedicare/overview/

17. Baldwin LM, Adamache $W$, Klabunde CN, et al. Linking physician characteristics and Medicare claims data: issues in data availability, quality, and measurement. Med Care 2002;40(Suppl):IV-82-95.
18. Ferrante JM, McCarthy EP, Gonzalez EC, et al. Primary care utilization and colorectal cancer outcomes among Medicare beneficiaries. Arch Intern Med 2011;171:1747-1757.

19. Warren JL, Harlan LC, Fahey A, et al. Utility of the SEER-Medicare data to identify chemotherapy use. Med Care 2002;40(Suppl):IV-55-61.

20. Yabroff KR, Warren JL, Banthin J, et al. Comparison of approaches for estimating prevalence costs of care for cancer patients: what is the impact of data source? Med Care 2009;47(Suppl 1):S64-69.

21. Heckler MM. Report of the Secretary's Task Force on Black and Minority Health, Vol. I: Executive Summary. Accessed August 4, 2020. Available at: https://minorityhealth.hhs.gov/assets/pdf/checked/1/ANDERSON.pdf

22. Gaubatz ME, Bukatko AR, Simpson MC, et al. Racial and socioeconomic disparities associated with 90-day mortality among patients with head and neck cancer in the United States. Oral Oncol 2019;89:95-101.

23. Ward E, Halpern M, Schrag N, et al. Association of insurance with cancer care utilization and outcomes. CA Cancer J Clin 2008;58:9-31.

24. Balasubramanian BA, Garcia MP, Corley DA, et al. Racial/ethnic differences in obesity and comorbidities between safety-net- and non safetynet integrated health systems. Medicine (Baltimore) 2017;96:e6326.

25. Noël RA. Race, Economics, and Social Status. Accessed August 4, 2020 Available at: https://www.bls.gov/spotlight/2018/race-economics-andsocial-status/pdf/race-economics-and-social-status.pdf

26. Boscoe FP, Johnson CJ, Sherman RL, et al. The relationship between area poverty rate and site-specific cancer incidence in the United States. Cancer 2014;120:2191-2198.

27. Semega J, Kollar M, Creamer J, Mohanty A. Income and Poverty in the United States: 2018. Accessed September 1, 2019. Available at: https:// www.census.gov/library/publications/2019/demo/p60-266.html

28. Shi X, Zhang TT, Hu WP, et al. Marital status and survival of patients with oral cavity squamous cell carcinoma: a population-based study. Oncotarget 2017;8:28526-28543.

29. Howren MB, Christensen AJ, Hynds Karnell L, et al. Influence of pretreatment social support on health-related quality of life in head and neck cancer survivors: results from a prospective study. Head Neck 2013;35: 779-787.

30. Inverso G, Mahal BA, Aizer AA, et al. Marital status and head and neck cancer outcomes. Cancer 2015;121:1273-1278.

31. Siegel RL, Jacobs EJ, Newton CC, et al. Deaths due to cigarette smoking for 12 smoking-related cancers in the United States. JAMA Intern Med 2015;175:1574-1576.

32. Ferrante JM, Lee JH, McCarthy EP, et al. Primary care utilization and colorectal cancer incidence and mortality among Medicare beneficiaries: a population-based, case-control study. Ann Intern Med 2013;159:437-446.

33. Fisher KJ, Lee JH, Ferrante JM, et al. The effects of primary care on breast cancer mortality and incidence among Medicare beneficiaries. Cancer 2013;119:2964-2972.

34. Robinson CD, Wiseman KP, Hooper MW, et al. Engagement and shortterm abstinence outcomes among blacks and whites in the National Cancer Institute's SmokefreeTXT program [published online September 19, 2019]. Nicotine Tob Res, doi: 10.1093/ntr/ntz178

35. Grobe JE, Goggin K, Harris KJ, et al. Race moderates the effects of motivational interviewing on smoking cessation induction. Patient Educ Couns 2020;103:350-358. 
36. Soril LJ, Leggett LE, Lorenzetti $\mathrm{DL}$, et al. Characteristics of frequent users of the emergency department in the general adult population: a systematic review of international healthcare systems. Health Policy 2016; 120:452-461.

37. Moe J, Kirkland S, Ospina MB, et al. Mortality, admission rates and outpatient use among frequent users of emergency departments: a systematic review. Emerg Med J 2016;33:230-236.

38. Arnett MJ, Thorpe RJ Jr, Gaskin DJ, et al. Race, medical mistrust, and segregation in primary care as usual source of care: findings from the exploring health disparities in Integrated Communities Study. J Urban Health 2016;93:456-467.

39. National Ambulatory Medical Care Survey: 2016 National Summary Tables. Accessed August 1, 2019. Available at: https://www.cdc.gov/nchs/ data/ahcd/namcs_summary/2016_namcs_web_tables.pdf

40. Chen J, Vargas-Bustamante A, Mortensen K, et al. Racial and ethnic disparities in health care access and utilization under the Affordable Care Act. Med Care 2016;54:140-146.

41. Lang K, Menzin J, Earle CC, et al. The economic cost of squamous cell cancer of the head and neck: findings from linked SEER-Medicare data. Arch Otolaryngol Head Neck Surg 2004;130:1269-1275.

42. Hollenbeak CS, Kulaylat AN, Mackley H, et al. Determinants of Medicare costs for elderly patients with oral cavity and pharyngeal cancers. JAMA Otolaryngol Head Neck Surg 2015;141:628-635.

43. Molina MA, Cheung MC, Perez EA, et al. African American and poor patients have a dramatically worse prognosis for head and neck cancer: an examination of 20,915 patients. Cancer 2008;133:2797-2806.

44. Dodd VJ, Watson JM, Choi Y, et al. Oral cancer in African Americans: addressing health disparities. Am J Health Behav 2008;32:684-692.

45. Powell W, Richmond J, Mohottige D, et al. Medical mistrust, racism, and delays in preventive health screening among African-American men. Behav Med 2019;45:102-117.
46. Rhee TG, Marottoli RA, Van Ness PH, et al. Impact of perceived racism on healthcare access among older minority adults. Am J Prev Med 2019;56: 580-585.

47. Liu JH, Zingmond DS, McGory ML, et al. Disparities in the utilization of high-volume hospitals for complex surgery. JAMA 2006;296:1973-1980.

48. Huang LC, Ma Y, Ngo JV, et al. What factors influence minority use of National Cancer Institute-designated cancer centers? Cancer 2014;120: 399-407.

49. David JM, Ho AS, Luu M, et al. Treatment at high-volume facilities and academic centers is independently associated with improved survival in patients with locally advanced head and neck cancer. Cancer 2017;123: 3933-3942.

50. Chen LM, Li G, Reitzel LR, et al. Matched-pair analysis of race or ethnicity in outcomes of head and neck cancer patients receiving similar multidisciplinary care. Cancer Prev Res (Phila) 2009;2:782-791.

51. Jackson CS, Gracia JN. Addressing health and health-care disparities: the role of a diverse workforce and the social determinants of health. Public Health Rep 2014;129(Suppl 2):57-61.

52. Jean-Pierre $P$, Hendren S, Fiscella K, et al. Understanding the processes of patient navigation to reduce disparities in cancer care: perspectives of trained navigators from the field. J Cancer Educ 2011 26:111-120.

53. O'Keefe EB, Meltzer JP, Bethea TN. Health disparities and cancer: racia disparities in cancer mortality in the United States, 2000-2010. Front Public Health 2015;3:51.

54. Kuo TM, Mobley LR. How generalizable are the SEER registries to the cancer populations of the USA? Cancer Causes Control 2016;27: 1117-1126.

55. Ragin C, Liu JC, Jones G, et al. Prevalence of HPV infection in racial-ethnic subgroups of head and neck cancer patients. Carcinogenesis 2017;38: 218-229. 
Supplemental online content for:

\section{Elderly Black Non-Hispanic Patients With Head and Neck Squamous Cell Cancer Have the Worst Survival Outcomes}

Jessica D. McDermott, MD; Megan Eguchi, MPH; Rustain Morgan, MD; Arya Amini, MD; Julie A. Goddard, MD; Evelinn A. Borrayo, PhD; and Sana D. Karam, MD, PhD

J Natl Compr Canc Netw 2021;19(1):57-67

eTable 1: Descriptive Statistics of Patients by Race/Ethnicity

eTable 2: Effects of Individual Covariates on Cancer-Specific Survival Differences in All Racial/Ethnic Groups 


\section{eTable 1. Descriptive Statistics of Patients by Race/Ethnicity}

\begin{tabular}{|c|c|c|c|c|c|}
\hline Characteristic & $\begin{array}{l}\text { White Non-Hispanic } \\
(\%)\end{array}$ & $\begin{array}{c}\text { Black Non-Hispanic } \\
(\%)\end{array}$ & $\begin{array}{l}\text { Hispanic } \\
(\%)\end{array}$ & $\begin{array}{c}\text { Asian Non-Hispanic } \\
(\%)\end{array}$ & P Value ${ }^{a}$ \\
\hline Patients, $\mathrm{n}$ & 10,858 & 994 & 725 & 540 & \\
\hline Sex & & & & & .029 \\
\hline Female & 30.3 & 27.0 & 27.0 & 32.0 & \\
\hline Male & 69.7 & 73.0 & 73.0 & 68.0 & \\
\hline Age, y & & & & & $<.001$ \\
\hline $66-74$ & 51.0 & 63.9 & 53.1 & 46.8 & \\
\hline $75-84$ & 34.8 & 28.6 & 34.8 & 36.5 & \\
\hline$\geq 85$ & 14.2 & 7.5 & 12.1 & 16.7 & \\
\hline Marital status & & & & & $<.001$ \\
\hline Unmarried & 47.2 & 69.3 & 50.3 & 35.2 & \\
\hline Married/Partnered & 52.8 & 30.7 & 49.7 & 64.8 & \\
\hline Registry region & & & & & $<.001$ \\
\hline East & 19.3 & 18.0 & 16.1 & 8.3 & \\
\hline Midwest & 12.4 & 15.9 & 1.8 & 2.2 & \\
\hline South & 30.2 & 47.2 & 4.0 & 3.7 & \\
\hline West & 38.0 & 18.9 & 78.1 & 85.7 & \\
\hline Patient urban/rural recode category & & & & & $<.001$ \\
\hline Urban commuting area & 84.5 & 93.2 & 90.6 & 97.2 & \\
\hline Nonurban commuting area & 15.5 & 6.8 & 9.4 & 2.8 & \\
\hline \multicolumn{2}{|c|}{ Census tract percentage below poverty line } & & & & $<.001$ \\
\hline$<20 \%$ & 80.3 & 41.4 & 61.0 & 80.4 & \\
\hline$\geq 20 \%$ & 19.7 & 58.5 & 39.0 & 19.6 & \\
\hline \multicolumn{2}{|c|}{ Visited $\mathrm{NCl}$-designated CC or teaching hospital } & & & & $<.001$ \\
\hline No or unknown & 27.9 & 19.4 & 26.6 & 21.3 & \\
\hline $\mathrm{NCl}$-designated CC & 21.6 & 14.6 & 24.4 & 42.8 & \\
\hline Teaching hospital & 50.5 & 66.0 & 49.0 & 35.9 & \\
\hline Charlson comorbidity score & & & & & $<.001$ \\
\hline 0 & 45.7 & 37.3 & 44.4 & 50.0 & \\
\hline 1 & 25.2 & 25.7 & 24.3 & 22.8 & \\
\hline$\geq 2$ & 29.1 & 36.9 & 31.3 & 27.2 & \\
\hline Primary site & & & & & $<.001$ \\
\hline Lip and oral cavity & 27.7 & 14.1 & 27.6 & 31.3 & \\
\hline Oropharynx & 25.5 & 23.6 & 19.2 & 21.7 & \\
\hline Nasopharynx & 1.8 & 3.1 & 2.3 & 9.4 & \\
\hline Hypopharynx & 4.7 & 7.1 & 5.7 & 5.9 & \\
\hline Larynx & 30.5 & 47.0 & 35.6 & 23.3 & \\
\hline Salivary glands/overlapping/NOS & 9.7 & 5.0 & 9.7 & 8.3 & \\
\hline AJCC cancer stage & & & & & $<.001$ \\
\hline 1 & 28.1 & 17.4 & 23.7 & 26.3 & \\
\hline$\|$ & 15.1 & 13.6 & 16.0 & 14.6 & \\
\hline III & 16.6 & 18.6 & 19.2 & 16.1 & \\
\hline IVA, IVB, or IV NOS & 36.3 & 43.4 & 35.6 & 39.3 & \\
\hline IVC & 3.9 & 7.0 & 5.5 & 3.7 & \\
\hline
\end{tabular}




\section{eTable 1. Descriptive Statistics of Patients by Race/Ethnicity (cont.)}

\begin{tabular}{|c|c|c|c|c|c|}
\hline Characteristic & $\begin{array}{c}\text { White Non-Hispanic } \\
(\%)\end{array}$ & $\begin{array}{c}\text { Black Non-Hispanic } \\
(\%)\end{array}$ & $\begin{array}{l}\text { Hispanic } \\
\text { (\%) }\end{array}$ & $\begin{array}{c}\text { Asian Non-Hispanic } \\
(\%)\end{array}$ & P Value ${ }^{a}$ \\
\hline Receipt of treatment within 6 mo & & & & & $<.001$ \\
\hline No & 12.9 & 19.1 & 13.6 & 11.5 & \\
\hline Yes & 87.1 & 80.7 & 86.3 & 88.5 & \\
\hline Any visits with $\mathrm{PCP}$ in prior year & & & & & $<.001$ \\
\hline No & 19.1 & 23.8 & 24.4 & 22.6 & \\
\hline Yes & 80.9 & 76.2 & 75.6 & 77.4 & \\
\hline Any visits with otolaryngology in prior year & & & & & .035 \\
\hline No & 59.4 & 63.8 & 62.1 & 60.4 & \\
\hline Yes & 40.5 & 36.2 & 37.9 & 39.6 & \\
\hline Any ED visits in prior year & & & & & $<.001$ \\
\hline No & 68.7 & 55.0 & 66.5 & 75.4 & \\
\hline Yes & 31.3 & 45.0 & 33.5 & 24.6 & \\
\hline
\end{tabular}

Statistics are unweighted column percentages.

Abbreviations: CC, cancer center; ED, emergency department; NOS, not otherwise specified; PCP, primary care physician.

abold indicates statistically significant $P$ value. 


\section{eTable 2. Effects of Individual Covariates on Cancer-Specific Survival Differences in All} Racial/Ethnic Groups

\begin{tabular}{|c|c|c|c|c|c|c|c|c|}
\hline \multirow[b]{2}{*}{ Characteristic } & \multicolumn{2}{|c|}{ Base Model $^{a}$} & \multicolumn{2}{|c|}{$\begin{array}{c}\text { Base Model + } \\
\text { SES }^{\mathrm{a}}\end{array}$} & \multicolumn{2}{|c|}{$\begin{array}{l}\text { Base Model + } \\
\text { SES + Stage }\end{array}$} & \multicolumn{2}{|c|}{$\begin{array}{c}\text { Base Model + } \\
\text { SES + Stage + } \\
\text { Treatment }^{\mathbf{a}}\end{array}$} \\
\hline & HR & $P$ Value & HR & $P$ Value & HR & $P$ Value & HR & $P$ Value \\
\hline Sex & & .004 & & .002 & & .001 & & $<.001$ \\
\hline Male & Ref & & Ref & & Ref & & Ref & \\
\hline $66-74$ & Ref & & Ref & & Ref & & Ref & \\
\hline $75-84$ & 1.29 & & 1.29 & & 1.38 & & 1.34 & \\
\hline$\geq 85$ & 1.84 & & 1.85 & & 2.03 & & 1.78 & \\
\hline Race/Ethnicity & & $<.001$ & & $<.001$ & & .209 & & .898 \\
\hline Asian $\mathrm{NH}$ & 0.94 & & 0.94 & & 0.92 & & 0.94 & \\
\hline Marital status & & $<.001$ & & $<.001$ & & $<.001$ & & $<.001$ \\
\hline Married/Partnered & Ref & & Ref & & Ref & & Ref & \\
\hline Unmarried & 1.52 & & 1.49 & & 1.41 & & 1.30 & \\
\hline Geographic region & & .005 & & .092 & & .028 & & .020 \\
\hline West & Ref & & Ref & & Ref & & Ref & \\
\hline East & 0.90 & & 0.91 & & 0.90 & & 0.93 & \\
\hline Midwest & 1.03 & & 1.03 & & 1.04 & & 1.02 & \\
\hline South & 1.07 & & 1.03 & & 1.03 & & 1.08 & \\
\hline Hypopharynx & 1.80 & & 1.80 & & 1.93 & & 1.78 & \\
\hline Larynx & 0.67 & & 0.67 & & 1.35 & & 1.28 & \\
\hline Lip and oral cavity & 0.73 & & 0.73 & & 1.41 & & 1.57 & \\
\hline Nasopharynx & 1.22 & & 1.22 & & 1.44 & & 1.34 & \\
\hline Salivary gland/overlapping/NOS & 0.93 & & 0.93 & & 1.35 & & 1.60 & \\
\hline Patient location & & - & & .694 & & .584 & & .939 \\
\hline Urban commuting & - & & Ref & & Ref & & Ref & \\
\hline Nonurban commuting & - & & 0.98 & & 1.02 & & 1.02 & \\
\hline Census tract percentage below poverty level & & - & & $<.001$ & & .005 & & .057 \\
\hline$<20 \%$ & - & & Ref & & Ref & & Ref & \\
\hline$\geq 20 \%$ & - & & 1.18 & & 1.12 & & 1.08 & \\
\hline Visited $\mathrm{NCl}$-designated $\mathrm{CC}$ or teaching hospital & & - & & .137 & & $<.001$ & & $<.001$ \\
\hline No or unknown & - & & Ref & & Ref & & Ref & \\
\hline $\mathrm{NCl}$-designated CC & - & & 0.97 & & 0.80 & & 0.98 & \\
\hline Teaching hospital & - & & 1.05 & & 0.97 & & 1.15 & \\
\hline
\end{tabular}




\section{eTable 2. Effects of Individual Covariates on Cancer-Specific Survival Differences in All} Racial/Ethnic Groups (cont.)

\begin{tabular}{|c|c|c|c|c|c|c|c|c|}
\hline \multirow[b]{2}{*}{ Characteristic } & \multicolumn{2}{|c|}{ Base Modela } & \multicolumn{2}{|c|}{$\underset{\text { SES }^{\mathrm{a}}}{\text { Base Model + }}$} & \multicolumn{2}{|c|}{$\begin{array}{l}\text { Base Model + } \\
\text { SES + Stage }\end{array}$} & \multicolumn{2}{|c|}{$\begin{array}{c}\text { Base Model + } \\
\text { SES + Stage + } \\
\text { Treatment }^{\text {a }}\end{array}$} \\
\hline & HR & $P$ Value & HR & $P$ Value & HR & $P$ Value & HR & $P$ Value \\
\hline AJCC cancer stage & & - & & - & & $<.001$ & & $<.001$ \\
\hline I & - & & - & & Ref & & Ref & \\
\hline II & - & & - & & 2.83 & & 2.57 & \\
\hline IVA, IVB, or IV NOS & - & & - & & 8.33 & & 7.87 & \\
\hline IVC & - & & - & & 19.47 & & 14.96 & \\
\hline Treatment & & - & & - & & - & & $<.001$ \\
\hline None & - & & - & & - & & Ref & \\
\hline Surgery + chemotherapy & - & & - & & - & & 0.34 & \\
\hline Surgery + RT & - & & - & & - & & 0.19 & \\
\hline Surgery + RT + chemotherapy & - & & - & & - & & 0.21 & \\
\hline Surgery alone & - & & - & & - & & 0.21 & \\
\hline
\end{tabular}

Year of diagnosis was included in the analysis but excluded from the table.

Abbreviations: CC, cancer center; HR, hazard ratio; NH, non-Hispanic; NOS, not otherwise specified; RT, radiation therapy; SES, socioeconomic status. abold indicates statistically significant values. 